\title{
Analysis of Existing Problems and Countermeasures of Multimodal Transport Development in Western Region
}

\author{
Zhigao Liao $^{\mathrm{a}}$ and Qian Zhu ${ }^{\mathrm{b}}$
}

School of Management, Guangxi University of Science and Technology, Liuzhou 545006, China

aLiaozhigao@126.com, 'bhuqian678@126.com

Keywords: Western; Multimodal transport; Existing problems; Countermeasures

\begin{abstract}
Western inland trade have developed quickly in our country in recent years, but it is still far inferior to the eastern coastal and central regions overall, so it is necessary to find out the existing problems in the development of western region of multimodal transport in our country. This paper analyzes the current situation of the development of multimodal transport in western China, points out the problems existing in the western region development of multimodal transport and proposes the corresponding countermeasures and Suggestions, which will help speed up the western region of multimodal transport network construction and further improve the operational efficiency of the western region multimodal transport network.
\end{abstract}

\section{Introduction}

Multimodal transport is to promote the joint Unicom of regional railways, highways, waterways, aviation and other transportation means, it is also to optimize the transport capacity and integrate transportation resources, reduce logistics costs, reduce logistics links, which will achieve seamless of freight and gradually formed the modern logistics integration of comprehensive transportation system ${ }^{[1]}$. As the development of "one belt, one road" strategy and western channel, our country puts forward higher requirements on multimodal transport in western China.

\section{The Advantages of Multimodal Transport}

Multimodal transport is a process of choosing two or more modes of transportation comprehensively, the characteristics of multimodal transport will be played a role according to the advantages of different mode of transportation based on the actual transportation situation to choice and the combination of the mode of transportation. Logistics process is composed of transportation; different mode of transportation is the basic conditions and method for the realization of the logistics. The reasonable and effective selection of transportation mode can not only improve the efficiency of transportation, reduce transportation time, reduce logistics cost and also can improve the transportation service quality, alleviate traffic pressure, improve the transport economic benefit. Multimodal transport is the important direction of current and future transport development; there are several advantages of multimodal transport as follows ${ }^{[2]}$ :

Unification and Simplistic. Unification and simplistic are revealed in the intermodal transportation mode, no matter the transport distance, the transshipment times, the change of the mode of transportation and loading and unloading of goods, all these shipping affairs are directed by the multimodal transport operator. The shipper of Multimodal transport needs only sign a contract of carriage, a check, paid once under the multimodal transport and multimodal transport operator shall be responsible for the entire carriage. The carrier of different extents on the mode of transportation is responsible for multimodal transport operator, such as goods damage in the process of transport; however the multimodal transport operator shall be responsible for the shipper.

Shorten the Time and Improve the Quality of Transportation. Multimodal transport is commonly by a unit as a container for the entire transport. Goods on the delivery location will arrive at the consignee directly by professional handling equipment to uniform loading and 
unloading of container cargo without changing box and packing in transit. There is no need to change box and pack, so it reduces a lot of the intermediate links, shortens the time of transport of the goods in the process of transportation. In addition, loading and unloading transport unit with professional equipment in the process of transfer which would help to reduce the cargo damage rate and improve the quality of goods freight greatly. Besides there are good coordination and compact cohesion between the various modes and ways of transportation which make the cargo turnover more smoothly in a timely manner and further reduce the transit time.

Reduce the Transportation Cost, Save the Freight. Multimodal transport shipper only needs to deal with the multimodal transport operator and the shipper will get the shipping documents from the multimodal transport operator. Compared with previous segmented mode of transportation that shippers have to deal with the carrier in all stages of transportation, multimodal transport shortens the transportation time, reduces the interest expenses and also realizes the door to door transportation. In general, the multimodal transportation not only saves material, manpower and financial resources, but also accelerates the capital turnover, brings great convenience to the shippers and is favorable for further development of transportation and logistics.

Improve the Level of Transport Organization and the Operating Efficiency. Multimodal transport can effectively strengthen the transformation and cohesion between each transportation mode, so as to improve the level of transport organization and realize the rationalization of transportation. Segmented mode of transportation established its own system and there is no relationship of each section of the transport, so there are many limitations on freight orders and transport business scope of each section. Besides the shippers must establish relationship with multiple carriers, which cause great trouble to the shippers. Multimodal transport is composited by different transport carriers and there is only one operator contact with the shipper directly, which is not only beneficial to the expansion of business scope, the multimodal transport operator can also use all kinds of transportation equipment effectively. All of these help multimodal transport shippers choose the best transport routes and modes of transport and realize the rationalization of transportation.

Other Effects. The development of multimodal transport is not only beneficial to the multimodal transport operators and shippers; it also has important significance to the government. It is mainly reflected in the following: the development of multimodal transport is conducive to control and supervise the cargo transportation chain on the macro for government; it is advantageous to the maximum reasonable use of the basic equipment of multimodal transport, saving resources, control expenses to increase revenue; it can reduce the damage to the environment of the transport industry and further protect the ecological environment through the management and guidance of multimodal transport by our country; multimodal transport can strengthen the trade between our country and other countries and promote the development of economy.

\section{The Development of Multimodal Transport in the Western Regions of China}

The western region of China has a natural advantage in nonferrous mineral resources and coal, agricultural products, petroleum and natural gas, and basic energy sources. However it is difficult to get out of resources of raw materials in the western region and it is also difficult to come for cheap consumer goods in the eastern coast. As the investment environment in the western region, the eastern region is relatively poor, so all kinds of investors are discouraged. The demand for consumer goods of the western region is enormous, but the consumption capacity is insufficient. Although investments in other industries are relatively small, the traffic is not convenient and the freight rates are higher, so as to the high total investment cost and the low rate of return on investment. All for those it is very difficult to develop economic for western region of china ${ }^{[3]}$.

Characteristics of Road Network. Our country are continuously building new highways and railways in the western region of China, but it is still in the initial stage of development on the whole. From the line of traffic mileage and civilian trucks, the western region logistics facilities are relatively small, especially in the construction of highways, which is far behind the east and the 
central region. The freight volume is difficult to match the construction of logistics infrastructures, making use of the new expressway was relatively low. In recent years, the western region mainly used logistics construction materials from rural to urban regions, these goods are often overloaded to reduce costs, which often results in destruction of the pavement and increasing the rate of traffic accidents.

The western development strategy and "one belt one road" strategy lay the policy basis and development rules for the logistics of the western region. Since the implementation of the western development strategy, our country has increased the support efforts to the ecological construction and infrastructure in the western region, which has improved the communication, traffic, environment infrastructure and especially provides a strong enhancement of transportation conditions for the development of the logistics industry.

The Present Situation of Logistics. We must vigorously develop the logistics industry for the economic development in the western region. Since the implementation of the western development strategy, the traffic situation has greatly improved. Since the implementation of the western development strategy, the traffic situation has greatly improved, the total freight volume and freight turnover in the western region in 2014 continued to increase, the annual freight volume reached 11 billion 498 million 70 thousand tons compared to 10 billion 636 million 70 thousand tons in 2013, which increased $8.10 \%$. The volume of goods transportation reached 25880.19 tons in western region in 2014 compared to 24310.07 tons in 2013, which increased 6.46\%. The freight volume and turnover of the specific provinces and autonomous regions in Western China are shown in Fig. 1 and Fig. 2. From Fig. 1and Fig. 2 can be seen the total freight volume and freight turnover has kept leading position in Inner Mongolia over the years, the total freight volume and freight turnover has kept in a backward position in Tibet over the years. The gap of economic development between the western regions is also obvious. The good development trend of the road traffic in the western region has strengthened the logistics service ability, which provides a good support for the economic and social development of the western region. However, there still exist some gaps compared with the developed eastern region. Therefore it is necessary to understand the logistics development of the western region. With the optional planning and macro management of the government, continuing to increase logistics infrastructure investment and building a logistics information platform actively, the current status of western logistics industry would be changed.

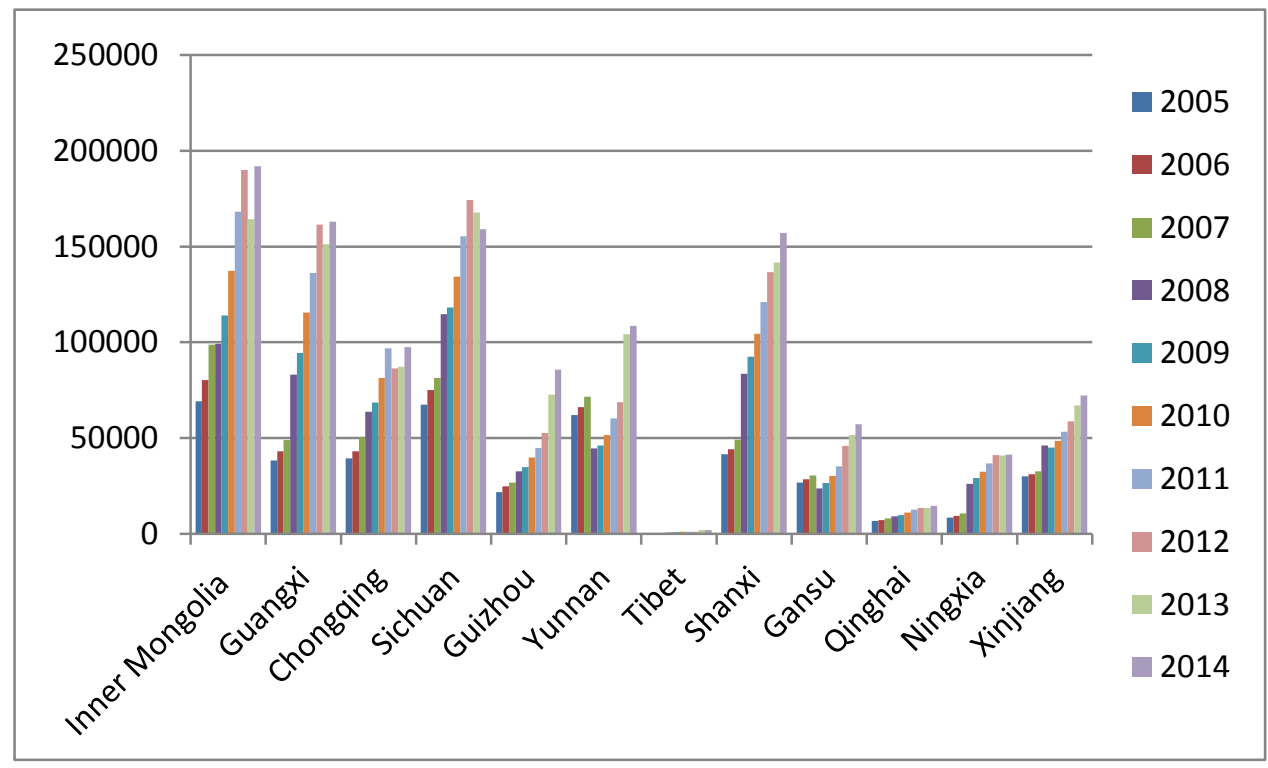

Figure 1. the freight volume of 12 provinces in west 


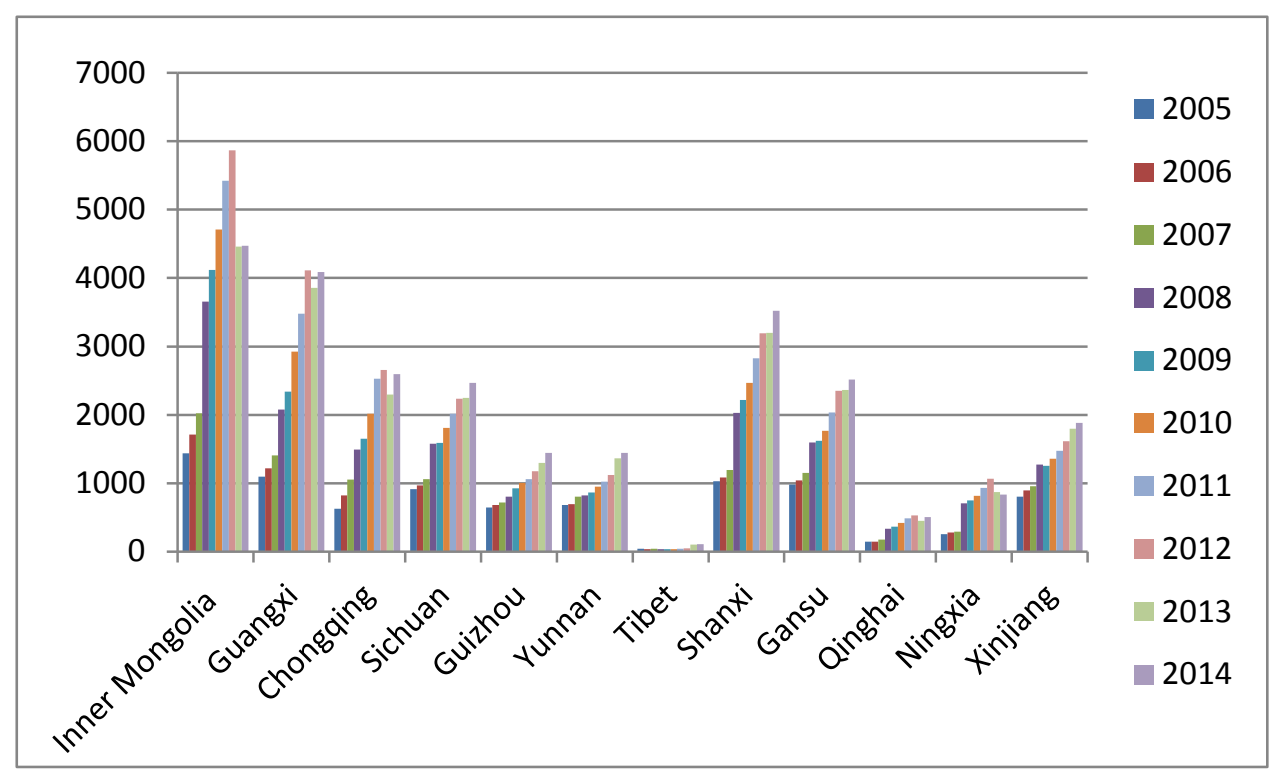

Figure 2. the freight turnover of 12 provinces in west

\section{Problems in the Development of Multimodal Transport in the Western Regions}

With the implementation of China's western development strategy and the economic development of the western region, multimodal transport in the western region of China has gained a certain degree of development. But due to the traditional way, the potential of multimodal transport has not been fully realized [4].

The Low Logistics Industry Market Concentration. The main reason for the low concentration of logistics market in the western region is limited by natural conditions. Although the western region is vast, but the harsh natural conditions, poor living conditions, low area population carrying capacity of 3000 meters above the Gobi desert and alpine area more than 3 million 200 thousand square kilometers, the total area of the western region around $60 \%$. Extremely harsh natural conditions constraint the western region's economic and social development, and increase the development cost. The low logistics industry market concentration degree leads to the low circulation of goods and the scattered distribution of goods, which is not conducive to the formation of hub cities and bring difficulties to the city's classification.

The Modern Logistics Industry in the Western Region is Under-Developed. The reasons for the slow development of modern logistics industry in the western region is very complex, including the development of the logistics industry's own conditions such as the imperfect infrastructure construction, the lack of logistics products and external environmental factors such as poor market concentration, the policy orientation is not strong and so on, but the most fundamental reason is the poor western region economic development. As an important part of modern third industry, logistics industry has a strong dependence on the development of regional economy.

Limited by the degree of economic development in the western region, the industrial system has not been established, the third industry development lags behind. As a new third industry, the economy of the logistics industry in the western region of the degree of attention can be imagined. The economic development is poor in the western region, and it will still take a period of time to form the logistics park and the hub of the city is difficult to define.

The Imperfect Logistics Industry Development System. Because of the unreasonable structure of logistics system in the western region, the distribution of logistics organization and the low degree of socialization, logistics industry has always been difficult to carry out large-scale, 
large-scale inter regional logistics services in the region. At present, many western enterprises still use the original set of logistics organizations, namely enterprises cover production, supply, sale links and so on. In the existing scale, western area logistics functions is not only single form but small scale which is difficult to form a covering a wide area of logistics network and to carry out effective regional scale logistics service.

\section{Analysis on the Development Strategy of Multimodal Transport in the Western Regions}

Coordinated Development of Various Modes of Transport. After years of development, the western region of China's highway construction and railway construction has made some progress, but the degree of development of intermodal rail transport and rail transport is low, so we should vigorously develop road-rail transport and ocean-rail transport to promote a variety of modes of transport seamlessly. At the same time, China's various transport departments should strengthen cooperation, give full play to the advantages of various modes of transport and take the implementation of flexible price strategy.

Improve the Management Level of the Organization of Multimodal Transport. Multimodal transport involves multiple stakeholder interests and it is a complex transport organization system, so it is necessary to organize the organization and coordination of the interests of all parties for professional transport agents. In the western region of China, the transportation market is developing rapidly, and the competition is becoming more and more competitive. However, more and more shipping agency companies are not mature. The rational agency business model can ensure the effective design of the optimal mode of transportation organization and the best transportation route, at the same time it can ensure the safety of goods delivered on time.

Strengthen the Construction of Transportation Information System. Transport information system is an important window for the transport business, the contract signing of the transport contract and the condition of cargo transport ${ }^{[5]}$. The railway transportation management information system improves the efficiency of railway transportation effectively, and realizes the sharing in the multimodal transport information accurately and timely in other modes of transport. It also provides convenience to the shipper and carrier about goods transportation condition.

The Rationalization of Transportation Tools and the Unification of Loading and Unloading Tools. Reasonable transportation tools and uniform loading and unloading tools are the basis of multimodal transport. Reasonable transportation tools and unified handling tools can not only reduce the operation time, improve the efficiency of transportation, but also ensure the safety of the transportation process and the handling process. At present, the multimodal transport and loading and unloading tools in the western region of China are not normal, and the technical level is not reasonable. Therefore, we should strengthen the construction of the basic materials such as transportation tools and loading and unloading tools.

\section{Conclusions}

The "Belt and Road" strategy and the western development strategy put forward higher requirement for the western region traffic conditions. The further development of economy in the western region can't be separated from the development of multimodal transport. We should aim at the problems faced by multimodal transport in the western region and take relevant measures from above four points.

\section{Acknowledgements}

(1)Guangxi Philosophy and Social Science Fund (The Grant No.13BGL009) 
(2)This research was supported by the outstanding young backbone teachers' training program in higher education institution of Guangxi, China.

\section{References}

[1] Liu Zhao-ran. Revelation of EU Inter-model Transport Policy on Developing Rail-sea Inter-model Transportation in China [J].Railway Transport and Economy, 2013, 05: 56-60.

[2] Wang $\mathrm{Xu}$. Revelation and Thoughts of Container Multimodal Transport Development in America [J].Railway Transport and Economy, 2016, 05:91-94.

[3] Wang Tong, Bao Wen-yan. Thoughts of Container Multimodal Transport Development in Western regions $[\mathrm{J}]$ Transportation enterprise management, 2013, 12:50-52.

[4] Zhang Yun. Development prospect of railway container multimodal transport in Chongqing [J]. Integrated Transportation, 2009, 06:69-72.

[5] Zhou Yong, Xie Xiao-song, Sun Huan-huan. Research on the development strategy of container multimodal transport [J]. Railway Freight Transportation, 2012, 01:23-26. 